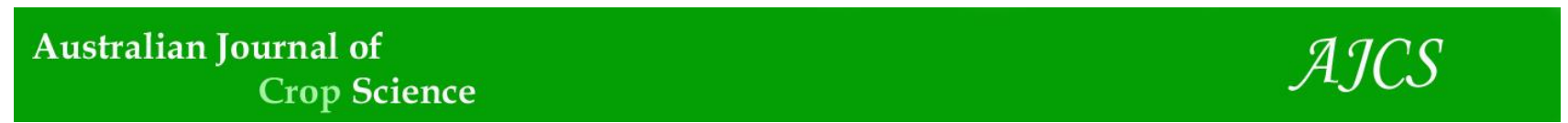

AJCS 15(06):925-932 (2021)

ISSN:1835-2707

doi: 10.21475/ajcs.21.15.06.p3171

\title{
Differential response of pea (Pisum sativum L.) genotypes to iron deficiency in relation to the growth, rhizosphere acidification and ferric chelate reductase activities
}

\section{Abdelmajid Krouma}

\author{
Research Unit Valorization and Optimization of Resources, Faculty of Sciences and Techniques of Sidi Bouzid, \\ University of Kairouan, Tunisia
}

*Corresponding author : abdelmajid.krouma@gmail.com

\section{Abstract}

Calcareous soils are known problematic lands for agricultural systems because of the low availability of nutrients, particularly iron (Fe). The so-called strategy I plant (e. g. Pea, Pisum sativum L.) which groups dicotyledons and monocots other than grasses, developed root membrane activities that contribute to the improvement of Fe availability. Among the functions considered to be a critical phase in iron absorption is rhizosphere acidification by H-ATPase and Fe(III) reduced by Fe(III) chelate reducctase (FeCR). In order to experimentally investigate the importance of root FeCR in Fe nutrition, its relationship with rhizosphere acidification and the genotypic differences in response to iron deficiency in pea (Pisum sativum L.), a glasshouse experiment was conducted hydroponically on four genotypes Merveille de Kelvedon (MK); Lincoln (Lin); Douce de Provence (DP) and Alexandra (Alex). Plants of each genotype were distributed into two plots, the first one received full nutrient solution (+ $\mathrm{Fe})$, the second one received nutrient solution devoid of iron (- Fe). Plant growth, Fe distribution, SPAD index and root acidification and ferric chelate reductase activities were evaluated. Fe deficiency decreased plant growth and SPAD index along with the significant increase of H-ATPase and FeCR activities. Some genotypic differences were observed as follows; Alex showed high tolerance to Fe deprivation as compared to other genotypes. Important H-ATPase and FeCR activities, high Fe use efficiency and adequate membrane efficiency are the main reasons for this tolerance. These physiological parameters could be used as tools of tolerance for further breeding programs.

Keywords: Fe-chelate reductase, Fe use efficiency, iron deficiency, membrane efficiency, rhizosphere acidification. Abbreviations: DW_dry weight, FeCR_ferric chelate reductase, FeUEFeCR_Fe use efficiency for ferric chelate reductase activity. FW_fresh weight, $M E_{-}$membrane efficiency

\section{Introduction}

Plant growth in the soil is a complex process. Roots play vital roles in anchoring and mechanical support of plants, absorption of water and nutrients, biosynthesis and storage of chemical compounds, and interactions with abiotic and biotic factors in the soil environment (Yu et al., 2019). Calcareous soils are one of these problematic areas, which constitute more than $30 \%$ of the planet's cultivated land (Wallace and Lunt, 1960). Mortvedt (1991) demonstrated that the soil solution does not provide more than $10 \%$ of Fe's plant requirements, leading to the so-called lime-induced chlorosis, affecting many annual crops and perennial plants. Iron is an essential element for almost all organisms due to its role in various metabolic processes. In plants, iron plays inevitable roles in intracellular metabolic pathways, such as electron transfer in photosynthesis and respiration (Briat et al., 2015; Nozoye et al., 2016), and is required for many enzymes in most living organisms to complete biological functions (Thomine and Vert, 2013). However, these achievements haven't helped to eliminate iron deficiency in the agricultural system. Iron deficiency annually affects numerous crop plants, which can cause a heavy reduction in fruit yield and quality (Zhao et al., 2020) pH is considered to be the main factor that affects the solubility of metals in the soil. The solubility of metals decreases at high $\mathrm{pH}$ and increases at low pH values (Sheoran et al., 2016). Multiple studies reported a range of adaptive mechanisms that evolve to increase plant tolerance to Fe deficiency. Plant tolerance to Fe deficiency is strongly correlated with the root ability to reduce rhizosphere $\mathrm{pH}$ by increasing proton extrusion and improving the ferric chelate reductase (FeCR) activity (Krouma et al., 2003). Reduction of Fe (III) to the more soluble form Fe (II) by FeCR enzyme located in the root cell plasma membrane seems to be a mandatory step in Fe uptake in Strategy I plant (Curie and Briat, 2003). This phenomenon which enhances Fe acquisition from the rhizosphere is one of the major physiological responses of plants to Fe deficiency (González-Vallejo et al., 2000; Krouma et al., 2003). Kosegarten et al. (2004) demonstrated that $\mathrm{FeCR}$ is highly sensitive to $\mathrm{pH}$ and is inhibited in alkaline soils. High soil $\mathrm{pH}$, often accompanied by an elevated bicarbonate concentration in calcareous soils is proposed to reduce root iron acquisition and transportation in plants (Karimi and Tari, 2017; Ding et al., 2019).

It is well established that the application of chemical $\mathrm{Fe}$ fertilizers effectively controls Fe chlorosis (Pestana et al., 2003). However, these fertilizers are costly and polluting the 
soil and environment. An environmentally friendly alternative strategy to improve crop production under Fedeficiency is organic, economical and sustainable methods to screen tolerant genotypes. The exploration of the genotypic differences in response to Fe deficiency to screen tolerant genotypes can represent the appropriate alternative. The present work consists of the exploration of the genotypic differences in the response of pea plants to $\mathrm{Fe}$ deficiency based on:

* Their capacity of rhizosphere acidification (H-ATPase),

* Fe chelate reductase (FeCR) activity,

* Fe use efficiency and,

* Membrane efficiency

Four pea (Pisum sativum L.) genotypes from the Ministry of Agriculture, Water resources and Fishing are used in a glasshouse experiment. A deep dissection of the relationship between H-ATPase, FeCR, Fe availability, chlorophyll and plant growth was made. Some new parameters such as Fe use efficiency and membrane efficiency were calculated to express the genotypic differences and highlight useful traits for further screening programs.

\section{Results}

\section{Plant growth and Fe nutrition}

Under iron deficiency, pea plants expressed Fe chlorosis symptoms on young leaves one week after the onset of the treatment. These visual symptoms were more severe in $\mathrm{MK}$, Lin and DP than in Alex. The SPAD index measurement, which reflects the leaves' chlorophyll status, confirmed this result (Table 1). Table 1 shows that iron deficiency decreased significantly the SPAD index in MK, Lin and DP (respectively by $31 \%, 28 \%$ and $28 \%$ ), with a less pronounced effect in Alex (13\%).

Plant growth also decreased under iron starvation in all genotypes. Some genotypic differences were observed (Table 1). Total fresh weight decreased by $25 \%$ in MK and DP, by $11 \%$ in Lin and no clear effect on Alex's growth. Alex's FW was 1.3 times more important than that of MK and DP cultivated under iron deficiency.

Measurements made on Fe repartition in the plant organs demonstrated that Fe concentrations decreased significantly in shoots and roots under deficient conditions. Nevertheless, plant organs are differently affected, Fe concentration in leaves decreased by less than $50 \%$ in all genotypes (Figure $1 \mathrm{a}$ in roots, Figure $1 \mathrm{~b})$. We calculated extractable Fe quantities in the plants to deeply analyze the Fe nutrition and repartition under problematic conditions (Table 1). Obtained results demonstrated that under Fe starvation, the accumulation of Fe were decreased significantly in plants with some genotypic differences. The quantities of $\mathrm{Fe}$ decreased by $65 \%, 51 \%, 58 \%$ and $43 \%$, respectively, in MK, Lin, DP and Alex when subjected to iron deficiency. Under these iron deficiency conditions, Alex accumulates $60 \%$, $30 \%$ and $60 \%$ more iron in its organs than MK, Lin and DP, respectively. This genotype remains the least affected, considering Fe concentration as well as Fe quantities.

\section{Root H-ATPase and FeCR activities}

The acidification capacity of roots was measured directly in the nutrient solution during 8 days of treatment. Figure 4 shows no clear modification of $\mathrm{pH}$ in control plants. Nevertheless, plants subjected to iron deficiency starts to acidify their nutrient solution one day after the onset of the treatment and continue during 5 days in MK and Lin (reaching the values of 5.3 and 5.21, respectively), 6 days in DP (reaching the value 5.27) and 7 days in Alex reaching the lowest value of $\mathrm{pH}$ (4.92) (Figure 2).

$\mathrm{FeCR}$ in roots was stimulated in stressed plants as compared to control ones. This stimulation was estimated to $15 \%$ in MK, $25 \%$ in Lin, $41 \%$ in DP and $80 \%$ in Alex (Figure 3 ). The genotypic differences that previously observed were maintained. FeCR was 1.4, 1.2 and 1.6 more important in Alex than MK, Lin and DP, respectively, under iron deficiency. We analyzed the between these physiological parameters modulating the genotypic differences in response to iron deficiency in pea. For the first time, we connected plant growth to their total Fe content (Figure 4). Fig 4a shows no relationship between biomass production and total $\mathrm{Fe}$ content in plants under sufficient Fe nutrition. Nevertheless, a close relationship occurs between plant growth and Fe content, when subjected to iron deficiency (Figure $4 b$ ). The genotype Alex is characterized by its high plant growth capacity and $\mathrm{Fe}^{2+}$ accumulation compared to the other ones. We represented the FeCR activity with root Fe concentration (Figure $5 \mathrm{a}, \mathrm{b}$ ). The first connection, a close relationship between Fe chelate reductase and root Fe concentration, is established under iron deficiency. As previously, Alex induces higher FeCR activity in its root membrane and remobilizes more iron.

Succeeding this in-depth analysis strategy of these physiological responses, we connected H-ATPase and FeCR activities in pea roots (Figure 6a, b). Fig 6a shows no relationship between H-ATPase and FeCR activities in control plants. When subjected to iron deficiency, a close and strict correlation between these two root membrane activities occurs. Alex also develops a higher capacity of root FeCR and $\mathrm{H}$-ATPase activities than the other genotypes.

\section{Discussion}

Our results show that iron deficiency-induced iron chlorosis in pea plants reduces plant growth and chlorophyll concentration with a clear distinction of Alex as the least affected than other genotypes. Previous studies demonstrated that iron is involved in chlorophyll and carotenoid biosynthesis (Morales et al., 1990; Thoiron et al., 1997), photosynthesis (Rutherford, 1985; Sandmann, 1985) as well as the metabolism of plastidial proteins (Spence et al., 1991). Therefore, the induced iron chlorosis and the decrease of chlorophyll concentration observed in this study can be explained by the drastic decrease of iron availability for these functions leading to growth fall. These results are those of Ksouri et al. (2007) on the grapevine, who demonstrated that lime-induced Fe shortage is genotypedependent. The growth parameters and leaf chlorophyll content were differently affected, depending on both genotype and bicarbonate dose. In Prunus rootstocks, Athanassios et al. (2005) demonstrated that Fe deficiency decreases plant growth and chlorophyll concentration and stimulates Fe- reductase activity. Valentinuzzi et al. (2020) demonstrated that Fe application to Fe deficient plants, even though at low levels (e.g. $1 \mu \mathrm{M}$ vs. $80-100 \mu \mathrm{M}$ in normal conditions), is sufficient to promote the reactivation of the primary metabolism in plants (e.g. photosynthesis, nitrogen acquisition and assimilation) with a consequent increase of the biomass accumulation. Other studies showed that iron deprivation decreased chlorophyll content in leaves and inhibited the Fe translocation to growing plant tissue (Bisht et al., 2002). 
Table 1. Different physiological parameters were measured in four Pea genotypes. + Fe: plants cultivated on a full nutrient solution, - Fe: plants cultivated on nutrient solution deprived of iron during 22 days. Means with the same letter are not significantly different at $p \leq 0.05$ according to Fisher's Least Significant Difference. Standard errors of means of 10 replicates.

\begin{tabular}{|c|c|c|c|c|c|c|c|c|}
\hline & \multicolumn{2}{|l|}{ MK } & \multicolumn{2}{|l|}{ Lin } & \multicolumn{2}{|l|}{ DP } & \multicolumn{2}{|l|}{ Alex } \\
\hline & $+\mathrm{Fe}$ & - Fe & $+\mathrm{Fe}$ & $-\mathrm{Fe}$ & $+\mathrm{Fe}$ & $-\mathrm{Fe}$ & $+\mathrm{Fe}$ & $-\mathrm{Fe}$ \\
\hline SPAD index & $38.6^{b} \pm 3.5$ & $26.5^{d} \pm 2.9$ & $39.8^{b} \pm 3.1$ & $28.7^{c} \pm 2.2$ & $42.4^{a} \pm 2.1$ & $30.5^{c} \pm 1.9$ & $44.3^{\mathrm{a}} \pm 1.7$ & $38.6^{b} \pm 2.3$ \\
\hline FW & $9.3^{b} \pm 1.23$ & $6.96^{c} \pm 1.42$ & $11.68^{a} \pm 1.35$ & $8.57^{b c} \pm 1.04$ & $78.99^{b} \pm 0.65$ & $6.34^{c} \pm 1.14$ & $11.98^{b} \pm 1.52$ & $10.04^{b} \pm 1.02$ \\
\hline $\mathrm{Fe}$ & $86.13^{\mathrm{a}} \pm 8.2$ & $30.45^{\dagger} \pm 4.5$ & $78.34^{b} \pm 9.2$ & $38.17^{\mathrm{e}} \pm 4.4$ & $74.16^{c} \pm 6.8$ & $30.86^{\dagger} \pm 3.5$ & $86.66^{a} \pm 6.8$ & $48.97^{d} \pm 5.2$ \\
\hline$\Delta \mathrm{pH}$ & $-0.23^{d} \pm 0.05$ & & $-0.40^{c} \pm 0.06$ & & $-0.59^{b} \pm 0.09$ & & $-1.09^{a} \pm 0.09$ & \\
\hline$\Delta \mathrm{FeCR}$ & $74.2^{d} \pm 8.2$ & & $104.7^{c} \pm 12.4$ & & $176^{b} \pm 20.1$ & & $372.3^{a} \pm 28.3$ & \\
\hline FeUE FeCR & $14.15^{\mathrm{d}} \pm 1.61$ & $44.26^{\mathrm{ab}} \pm 2.83$ & $12.39^{d} \pm 1.19$ & $31.68^{\mathrm{C}} \pm 2.72$ & $13.73^{\mathrm{d}} \pm 1.7$ & $41.43^{b} \pm 23$ & $12.44^{d} \pm 16$ & $47.31^{a} \pm 35$ \\
\hline ME & $82.4^{\mathrm{cd}} \pm 5.8$ & $98.5^{b c} \pm 6.3$ & $70^{d} \pm 7.1$ & $93.4^{c} \pm 8.3$ & $70.8^{d} \pm 7.2$ & $110.7^{b} \pm 13.2$ & $77.1^{\mathrm{cd}} \pm 6.1$ & $169.8^{a} \pm 20.1$ \\
\hline
\end{tabular}

* SPAD index, * FW, Fresh weight expressed as g. plant ${ }^{-1}, * \Delta \mathrm{pH}$, calculated as the difference between pH in stressed plants and $\mathrm{pH}$ in control ones,

$* \Delta \mathrm{FeCR}$, calculated as the difference between FeCR in stressed plants and FeCR in control ones, ${ }^{*} \mathrm{Fe}$, quantities of Fe measured in plants (Fe, $\mu$ g. plant ${ }^{-1}$ ),

* FeUE FeCR, Fe Use Efficiency for FeCR, calculated as the ratio of FeCR (nmol Fe ${ }^{2+} \cdot \mathrm{g}^{-1} \mathrm{FW}$ roots) to root Fe ( $\mu \mathrm{g}$. plant ${ }^{-1}$ ), ${ }^{*} \mathrm{ME}, \mathrm{Membrane}$ Efficiency, expressed as the ratio of FeCR to H-ATPase.
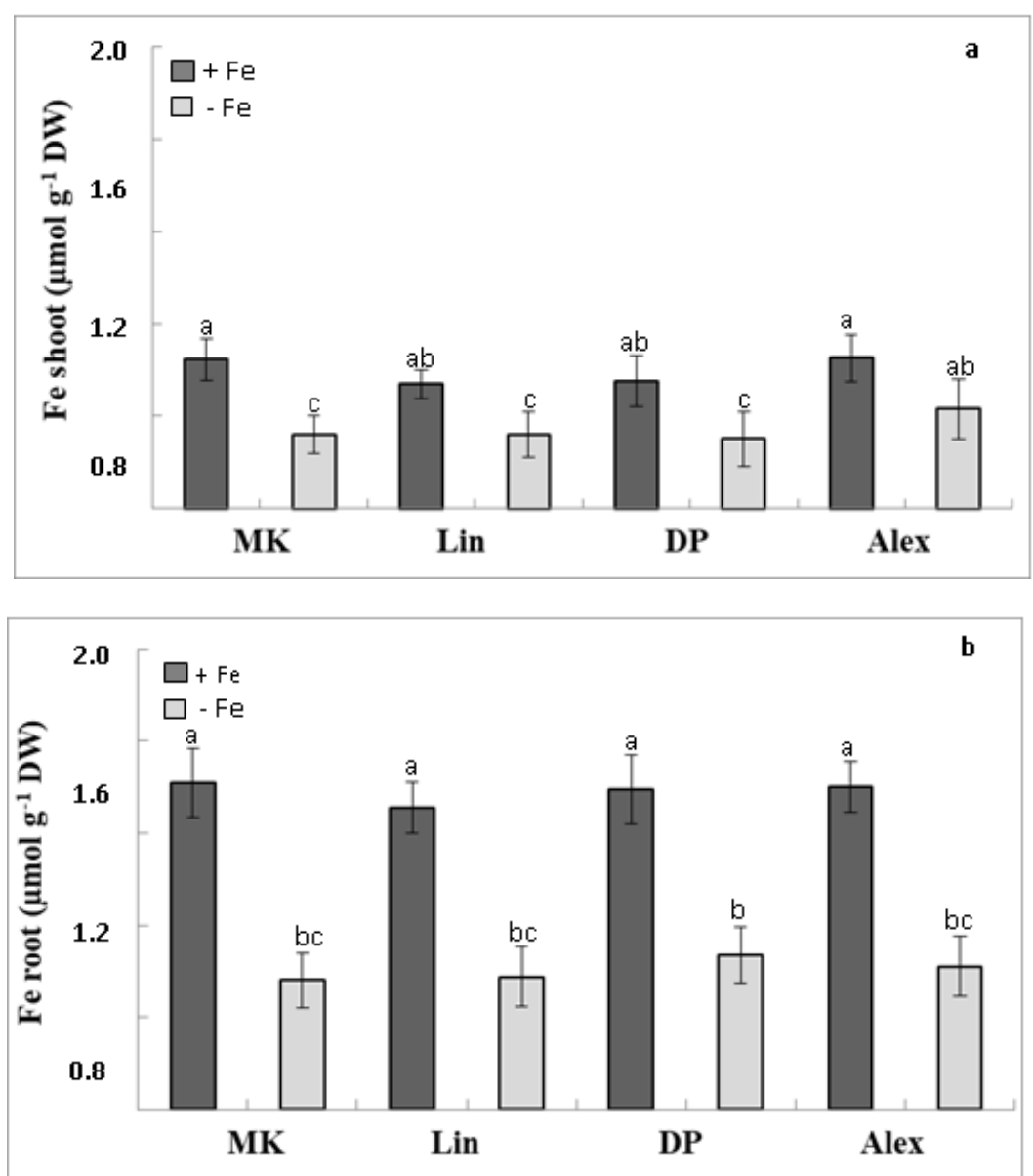

Figure 1. Extractible Fe $\left(\mathrm{Fe}^{2+}\right)$ concentration in shoots (a) and roots (b) of pea plants after 22 days of treatments. + Fe: control plants cultivated on standard nutrient solution, -Fe: plants cultivated on nutrient solution deprived from Fe. Within columns, means with the same letter are not significantly different at $p \leq 0.05$ according to Fisher's Least Significant Difference. Standard errors of means of 10 replicates.

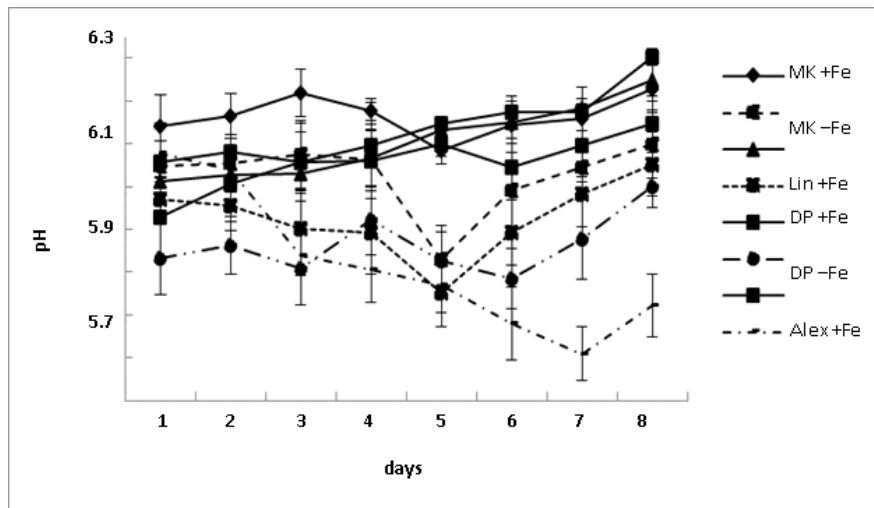

Figure 2. Root H-ATPase activity expressed as acidification capacity during 8 days. Measurements were made on plants subjected ($\mathrm{Fe}$ ) or no (+Fe) to iron deficiency during 2 weeks. Vertical bars represent \pm standard errors of means of 10 replicates, $p \leq 0.05$. 


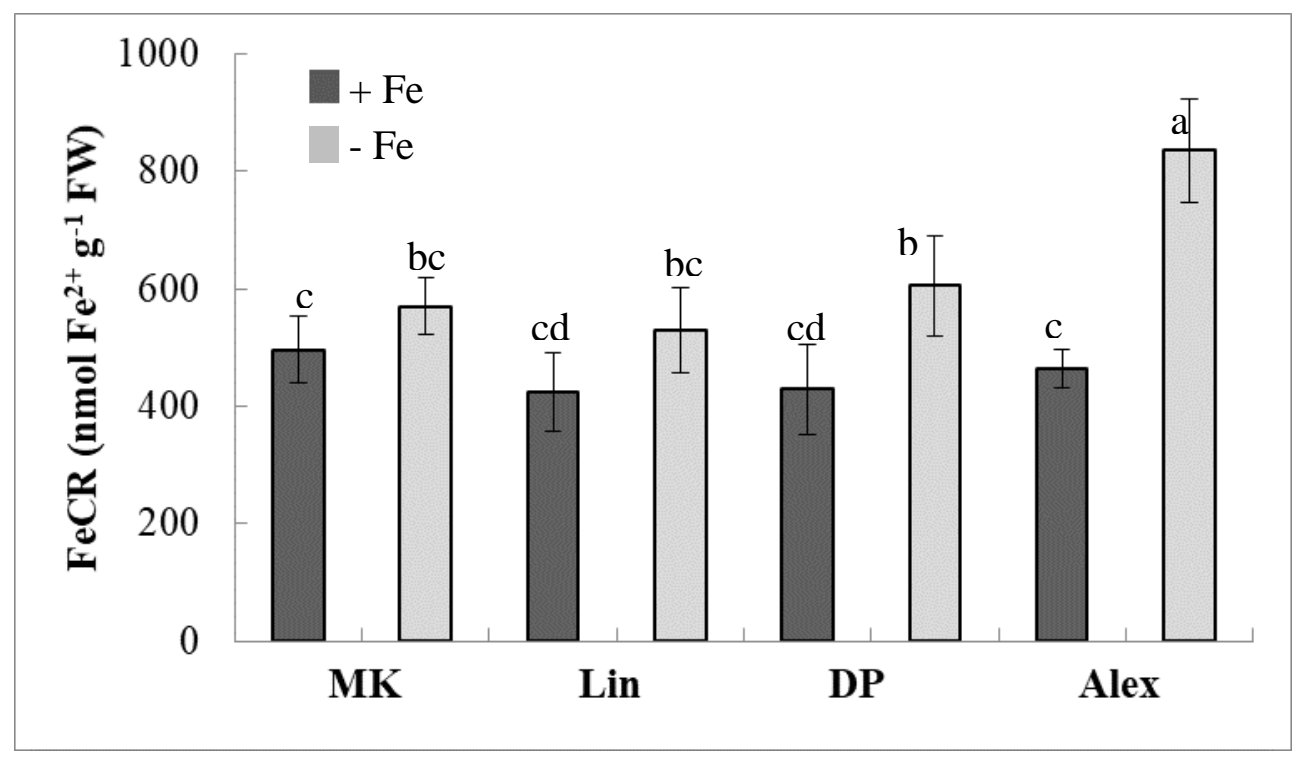

Figure 3. Fe(III)-chelate reductase (FeCR) activity in roots of Pea plants after 22 days of treatments. + Fe: control plants cultivated on standard nutrient solution, -Fe: plants cultivated on nutrient solution deprived from Fe. Within columns, means with the same letter are not significantly different at $p \leq 0.05$ according to Fisher's Least Significant Difference. Standard errors of means of 10 replicates.

Valipour et al. (2020) showed that both Fe deficiency (direct or lime induced) decreased leaf chlorophyll, carotenoid and Fe concentrations in quince seedlings. Lopez-Millan et al. (2001) concluded that chlorophyll biosynthesis is considered as an indicator of net physiologically available iron to the plant.

The genotypic differences previously observed in plant growth and chlorophyll accumulation are also maintained for Fe nutrition. Alex shows the least affected leaves and the most affected Fe concentration roots than the other genotypes. Nevertheless, it maintains the higher capacity of iron accumulation (Table 1). This result lets us think that the performance of Alex (represented by its capacity of plant growth and fewer chlorosis symptoms) is linked to its ability of iron uptake by roots and translocation to the shoots to support photosynthetic and other metabolic ways. This micronutrient calculation demonstrated that Alex accumulated up to $59 \%, 28 \%$ and $61 \%$ more Fe than DP, Lin and $\mathrm{MK}$, respectively (Table 1) under Fe starvation. At the same time, this genotype stimulated its FeCR more significantly (+ $80 \%$ as compared to control plants) than $\mathrm{MK}$ (+ $15 \%$ as compared to control plants), Lin (+ $25 \%$ as compared to control plants) and DP $(+41 \%$ as compared to control plants). Thus, we can explain Fe's critical improvement in Alex subjected to iron deficiency by its high $\mathrm{FeCR}$ induction capacity under such conditions. The $\triangle \mathrm{FeCR}$ calculated as the difference of FeCR between stressed and control plants (Table 1) is 5.1, 3.56 and 2.11 times more important in Alex than MK, Lin and DP, respectively. Similarly, our results show an important induction of $\mathrm{H}$ ATPase activity in all genotypes under Fe deficiency, but Alex is discriminated against by the other ones. The $\Delta \mathrm{pH}$ calculated as the $\mathrm{pH}$ difference between stressed and control plants (Table 1 ) is 4.7, 2.7 and 1.8 times more important in Alex than that of MK, Lin and DP, respectively. In light of these results, we can conclude that the rhizosphere acidification improvement constitutes a good environment for FeCR and confirms these two membrane activities' interdependence. Previously, Kosegarten et al. (2004) demonstrated that FeCR is highly sensitive to $\mathrm{pH}$ and is inhibited in alkaline soils. Karimi and Tari (2017) and Ding et al. (2019) demonstrated that high soil pH, often accompanied with an elevated bicarbonate concentration in calcareous soils, are proposed to reduce root iron acquisition and transportation in plants. Bicarbonate in the rhizosphere can also inhibit the iron reductase activity of roots by neutralizing protons released by $\mathrm{H}^{+}$-ATPase (Rabotti and Zocchi, 1994; Romera et al., 1992). Under iron-deficient conditions, pear, as a Strategy I plant, releases $\mathrm{H}^{+}$and phenolic compounds to the rhizosphere and up-regulates root ferric-chelate reductase activity to enhance $\mathrm{Fe}^{3+}$ reduction, and then the reductive $\mathrm{Fe}^{2+}$ was uptaken by IRT transporter proteins located at the cell membrane (Garnica et al., 2018; En-Jung and Waters, 2016). In this study, the relative tolerance to iron deficiency observed in Alex, as compared to MK, Lin and DP genotypes, seems to be linked to its high capacity of rhizosphere acidification which constitutes a good environment for the induction of FeCR enzyme leading to the improvement of Fell availability for the plant.

Nevertheless, the various connections established in this study demonstrated the close relationship between plant growth and its Fe accumulation (Figure 4), between FeCR and Fe concentration in roots (Figure 5) and between FeCR and H-ATPase (rhizosphere $\mathrm{pH}$ ). Thus, we can conclude the presence of a common thread between H-ATPase, FeCR, Fe content and plant growth. The tolerant genotype (Alex in this study) can acidify his rhizosphere, stimulating his FeCR activity to conduct a critical Fe remobilization and adequate plant growth. In order to explore more the variability of response to iron deficiency in pea genotypes and to identify other traits of tolerance, we calculated the Fe use efficiency for FeCR activity (FeUEFeCR). This parameter is calculated as the ratio of $\mathrm{FeCR}$ ( $\mathrm{nmol} \mathrm{Fe} \mathrm{g}^{2+} \mathrm{g}^{-1} \mathrm{FW}$ roots) to root Fe ( $\mu \mathrm{mol} \mathrm{g}$ 1 DW roots) (Table 1). All genotypes increased their FeUEFeCR when subjected to iron deficiency, and the genotypic differences previously observed were maintained. Alex expressed higher efficiency of Fe use for FeCR activity (+ $20 \%$ as compared to control plants; $+3 \%$ in MK and Lin and $+10 \%$ in DP) 


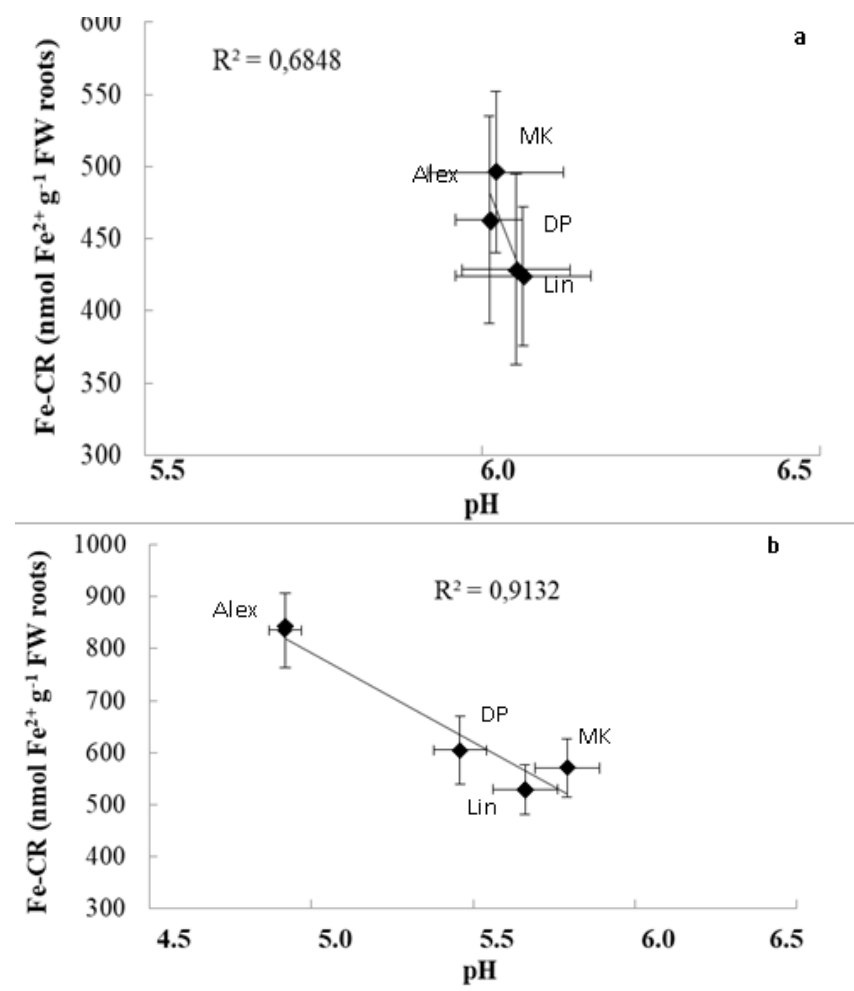

Figure 5. Relationship between ferric chelate reductase ( $n$ mol Fe $\mathrm{F}^{2+} \mathrm{FW}$ ) and root Fe concentration ( $\left.\mu \mathrm{mol} \mathrm{g}^{-1} \mathrm{DW}\right)$ in Pea plants cultivated on standard nutrient solution (a) or nutrient solution devoid of iron (b). Vertical and horizontal bars represent \pm standard errors of means of 10 replicates, $p \leq 0.05$.

Following this strategy of deep dissection of pea response to iron deficiency, we calculated the membrane efficiency (ME) expressed as the ratio of FeCR to H-ATPase (Table 1). All genotypes increased their ME when subjected to iron starvation. This stimulation was estimated to $20 \%, 33 \%, 56 \%$ and $120 \%$, respectively, in MK, Lin, DP and Alex. At this level, Alex was also distinguished by its higher root membrane efficiency. Even under Fe deficiency, ME was 1.7, 1.8 and 1.5 more important in Alex than MK, Lin and DP, respectively. In this study, we emphasise the relative tolerance of Alex compared to MK, Lin and DP. Such a genotypic variation in response of pea to $\mathrm{Fe}$ deficiency confirms previous intraspecific variations reported in green bean (Hemantaranjan and Garg, 1986), chickpea (Rai et al., 1982), lentil (Rai et al., 1984), peanut (O'Hara et al., 1988), lupine (Tang et al., 1990) and quince seedlings (Valipour et al., 2020). We suggest that iron deficiency-induced, firstly, roots H-ATPase, then root FeCR activity due to the new adequate condition of rhizosphere $\mathrm{pH}$, and finally produced $\mathrm{Fe}^{2+}$ is uptaked and allocated to shoots to support chlorophyll biosynthesis, photosynthesis and plant growth. In accordance with our results, Yi and Guerinot (1996) showed that root $\mathrm{FeCR}$ is necessary for $\mathrm{Fe}$ uptake under $\mathrm{Fe}$ deficiency. Santi et al. (2005) suggested that two plasma membrane H-ATPase genes are deferentially expressed in Fe-deficient plants.

\section{Materials and methods}

\section{Plant materials and growth conditions}

Four pea genotypes, Merveille de Kelvedon (MK), Lincoln (Lin), Douce de Provence (DP) and Alexandra (Alex), sourced from the Ministry of Agriculture, water resources and fishing are used. Healthy seeds of uniform size were disinfected with $2 \%$ Calcium hypochlorite solution and were germinated in Petri dishes. 6-day-old plantlets were transferred in a glasshouse, at the Faculty of Sciences and Techniques of Sidi Bouzid ( $\left.35^{\circ} 2^{\prime} 7.58^{\prime \prime} N 9^{\circ} 29^{\prime} 2.18^{\prime \prime} \mathrm{E}\right)$ under natural light with

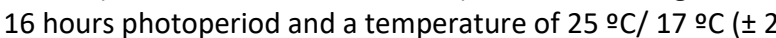
oC, day / night), relative humidity about $75 \%$ and using the following nutrient solution (Hewitt 1996): $\mathrm{Ca}(\mathrm{NO} 3) 2$ $(1.25 \mathrm{mM}), \mathrm{KNO} 3(1.25 \mathrm{mM}), \mathrm{KH} 2 \mathrm{PO} 4(1.60 \mathrm{mM}), \mathrm{MgSO}_{4}$ $(0.50 \mathrm{mM}), \mathrm{K}_{2} \mathrm{SO}_{4}(1.50 \mathrm{mM}), \mathrm{CaSO}_{4}(3.50 \mathrm{mM}), \mathrm{H}_{3} \mathrm{BO}_{3}(4$ $\mu \mathrm{M}), \mathrm{MnSO}_{4}(4 \mu \mathrm{M}), \mathrm{ZnSO}_{4}(1 \mu \mathrm{M}), \mathrm{CuSO}_{4}(1 \mu \mathrm{M}), \mathrm{CoCl}_{2}(0.12$ $\mu \mathrm{M}),(\mathrm{Na})_{6}(\mathrm{Mo})_{7} \mathrm{O}_{24}(0.12 \mu \mathrm{M})$.

\section{Experimental design}

Cultures were conducted hydroponically and individually in 1 $L$ pots, and plants were separated into two plots; the first one (10 pots) received the above nutrient solution added with $30 \mu \mathrm{M}$ Fe as K-Fe-EDTA (control plants, $+\mathrm{Fe}$ ), the second plot (10 pots) received the same nutrient solution without iron (stressed plants, - Fe). The nutrient solution was aerated with a flow of $400 \mathrm{ml} \mathrm{min}^{-1}$ of filtered air via a compressor and "spaghetti tube" distribution system and changed every 3 days during two weeks of treatment. After that (apparition of visual symptoms of chlorosis), nutrient solution $\mathrm{pH}$ was adjusted to 6 and measured daily for over 8 days. Finally, Fechelate reductase activity and SPAD index were performed, and plants were harvested for biomass and extractable $\mathrm{Fe}$ $\left(\mathrm{Fe}^{2+}\right)$ quantification. All measurements and expressed parameters are means of 10 replicates. 


\section{SPAD Index}

Relative leaf chlorophyll concentrations were estimated in vivo on the youngest fully expanded leaf using a SPAD-502 (Konica-Minolta, Japan). Measurements were made on 10 plants of each treatment. Presented results are means of 10 replicates per genotype and treatment. Values are expressed as SPAD units.

\section{Acidification capacity}

The acidification capacity was measured daily in the continuously aerated nutrient solution, adjusted to $\mathrm{pH} 6.0$ with $0.1 \mathrm{~N} \mathrm{NaOH}$ (Vizzotto et al. 1999).

\section{$\mathrm{Fe}$ (III) Chelate reductase}

the Fe-chelate reductase activity was measured in plant roots subjected to iron starvation for 8 days according to the method of Krouma et al. (2003) in $100 \mathrm{~mL}$ of a solution containing $0.5 \mathrm{mM}$ CaSO4, $0.1 \mathrm{mM}$ Fe(III)EDTA, $0.3 \mathrm{mM}$ bathophenanthrolinedisulfonic acid (BPDS) and $10 \mathrm{mM}$ 2-(Nmorpholin)ethane sulfonic acid (MES) adjusted to $\mathrm{pH} 5.5$ with $0.1 \mathrm{~N} \mathrm{NaOH}$. The Fe(II)BPDS3 complex's absorbance was measured at $535 \mathrm{~nm}$ based on the extinction coefficient of $22 \mathrm{mM} \mathrm{cm}^{-1}$.

\section{Iron determination}

$\mathrm{Fe}^{2+}$ extraction was made in powdered digested samples using the $\mathrm{HCl}$ method. $20 \mathrm{mg}$ of fine powder was digested in $5 \mathrm{ml}$ of $1 \mathrm{~N} \mathrm{HCl}$ for 4 hours, then $5 \mathrm{ml}$ of deionized water were added and the extract was filtered. Fe content was determined by the atomic absorption spectrophotometry method (Köseoglu and Açikgöz, 1995).

\section{Statistical analysis}

Data and statistical analyses were performed using the software StatPlus Pro. All data are presented as mean \pm standard error. Analysis of variance (ANOVA) was performed to determine whether the effects of treatments (+ Fe, $-\mathrm{Fe}$ ) on the respective factor were significant. The significance of differences among treatment means was determined by Fisher's least significant difference test (LSD) at $5 \%$. Treatment means were declared significantly when the difference between any two treatments was more significant than the LSD value generated from the ANOVA. They are marked by different letters in the figures.

\section{Conclusion}

The present study shows that plant growth, SPAD index, Fe nutrition, root $\mathrm{H}$-ATPase and root FeCR are interdependent. Our results confirm the relative tolerance of the genotype Alex to iron deficiency as compared to the other ones. The primordial reasons for this tolerance are its higher root membrane efficiency represented by the important capacity of rhizosphere acidification and Fe chelate reductase activity and its remarkable Fe use efficiency. FeUECR and ME discriminated against the studied genotypes and can be used as trait of tolerance for further screening programs.

\section{Funding}

This study was supported by the research Project DiVicia: Use and management of Vicia species for sustainability and resilience in biodiversity-based farming systems funded by PRIMA 2019 (Partnership for Research and Innovation in the Mediterranean Area)

\section{Acknowledgments}

We thank Prof. Chedly Abdelly, General Manager of the National Agency for Research Promotion and his Technical and Administrative staff for all facilities and financial management of the Project.

\section{References}

Athanassios NM, Grigorios CD, loannis NT, Vassilios T, Kortessa ND (2005) Oxidative stress, antioxidant activity and $\mathrm{Fe}(\mathrm{III})$-chelate reductase activity of five Prunus rootstocks explants in response to Fe deficiency. Plant Growth Regul. 46:69-78.

Bisht SS, Nautiyal BD, Sharma CP (2002) Biochemical changes under iron deficiency and recovery in tomato. Ind J Plant Physiol. 7:183-186.

Briat JF, Dubos C, Gaymard F (2015) Iron nutrition, biomass production, and plant product quality. Trends Plant Sci. 20:33-40

Curie C, Briat JF (2003) Iron transport and signaling in plants. Annu Rev Plant Biol. 54:183-206.

Ding WL, Clode PL, Lambers H (2019) Effects of pH and bicarbonate on the nutrient status and growth of three Lupinus species. Plant Soil. 447:9-28.

En-Jung H, Waters B (2016) Alkaline stress and iron deficiency regulate iron uptake and

riboflavin synthesis gene expression differently in root and leaf tissue: implications for iron deficiency chlorosis. J Exp Bot. 67(56):5671-5685.

Garnica M, Bacaicoa E, Mora V, Francisco SS, Baigorri R, Zamarreño AM, Garcia-Mina JM

(2018) Shoot iron status and auxin are involved in iron deficiency-induced phytosiderophores release in wheat. BMC Plant Biol. 18:1471-2229.

González-Vallejo EB, Morales F, Cistué L, Abadía A, Abadía J (2000) Iron deficiency

decreases the $\mathrm{Fe}(\mathrm{III})$-chelate reducing activity of leaf protoplasts. Plant Physiol. 122:337-344.

Hemantaranjan A, Garg OK (1986) Introduction of nitrogenfixing nodules through iron and zinc fertilization in the non-nodules-forming French bean (Phaseolus vulgaris L.). J Plant Nutr. 9:281-288.

Hewitt EJ (1966) Sand and water culture methods used in the study of plant nutrition, 2nd ed. Commonwealth Bureau of Horticulture Technical Communications, p. 22.

Karimi HR, Tari FE (2017) Effects of $\mathrm{NaHCO}$ on photosynthetic characteristics, and iron and sodium transfer in pomegranate. J Plant Nutr. 401:1-22.

Kosegarten H, Hoffmann B, Rroco E, Grolig F, Glüsenkamp $\mathrm{KH}$, Mengel $\mathrm{K}$ (2004) Apoplastic $\mathrm{pH}$ and $\mathrm{Fe}^{\mathrm{III}}$ reduction in young sunflower (Helianthus annuus) roots. Physiol Plant. 122:95-106.

Köseoglu AT, Açikgöz V (1995) Determination of iron chlorosis with extractable iron analysis in peach leaves. J Plant Nutr. 18:153-161.

Krouma A, Gharsalli M, Abdelly C (2003) Differences in response to iron deficiency among some lines of common bean. J Plant Nutr. 26:2295-2305.

Ksouri R, Debez A, Mahmoudi H, Ouerghi Z, Gharsalli M, Lachaâl M (2007) Genotypic variability within Tunisian grapevine varieties (Vitis vinifera L.) facing bicarbonateinduced iron deficiency. Plant Physiol Biochem. 45:315-322. 
Lopez-Millan AF, Morales F, Abadia A, Abadia J (2001) Changes induced by Fe deficiency and Fe resupply in the organic and metabolism of sugar beet (Beta vulgaris) leaves. Physiol Plant. 112:31-38.

Morales F, Abadia A, Abadia J (1990) Characterization of the xanthophyll cycle and other photosynthetic pigment changes induced by iron deficiency in sugar beet (Beta vulgaris L.) Pant Physiol. 94:607-613.

Mortvedt JJ (1991) Correcting iron deficiencies in annual and perennial plants: Present technologies and future prospects. Plant Soil. 130:273-279.

Nozoye T, Otani M, Senoura T, Nakanishi H, Nishizawa NK (2016) Overexpression of barley nicotianamine synthase 1 confers tolerance in the sweet potato to iron deficiency in calcareous soil. Plant Soil. 418:75-88.

O'Hara GW, Boonkerd N, Dilworth MJ (1988) Mineral constraints to nitrogen fixation. Plant Soil. 108:93-110.

Pestana M, de Varennes A, Faria EA (2003) Diagnosis and correction of iron chlorosis

in fruit trees: a review. J Food Agr Environ. 1:46-51.

Rabotti G, Zocchi G (1994) Plasma membrane-bound $\mathrm{H}^{+}$ATPase and reductase activities

in Fe-deficient cucumber roots. Physiol Plant. 90:779-785.

Rai R, Singh SN, Prasad V (1982) Effect of press mud amended pyrite on symbiotic $\mathrm{N}_{2}$-fixation, active iron contents of nodules, grain yield and quality of chickpea (Cicer arietinum Linn) genotypes in calcareous soil. J Plant Nutr. 5:905-913.

Rai R, Prasad V, Choudhury SK, Sinha NP (1984) Iron nutrition and symbiotic $\mathrm{N}_{2}$ fixation of lentil (Lens culinaris) genotypes in calcareous soil. J Plant Nutr. 7:399-405.

Romera FJ, Alcántara E, de La Guardia MD (1992) Effect of bicarbonate, phosphate and high $\mathrm{pH}$ on the reducing capacity of the Fe-deficient sunflower and cucumber plants. J Plant Nutr. 15: 1519-1530.

Rutherford AW (1985) Orientation of EPR signals arising from components in photosystem II membranes. Biochim Biophys Acta. 807:189-201.

Sandmann G (1985) Consequences of iron deficiency on photosynthetic and respiratory electron transport in bluegreen algae. Phot Res. 6:261-272.

Santi S, Cesco S, Varanini Z, Pinton R (2005) Two plasma membrane $\mathrm{H}^{+}$-ATPase genes differentially expressed in iron-deficient cucumber plants. Plant Physiol Biochem. 43: 287-292.
Sheoran V, Sheoran AS, Poonia P (2016) Factors affecting phytoextraction: a review. Pedosphere 26:148-166.

Spence MJ, Henzi MT, Lammers PJ (1991) The structure of a Phaseolus vulgaris CDNA encoding the iron storage protein ferritin. Plant Mol Biol. 117:499-504.

Tang C, Robson A, Dilworth MI (1990) The role of iron in nodulation and nitrogen fixation in Lupinus angustifolius $\mathrm{L}$. New Phytol. 114:173-182.

Thoiron S, Pascal N, Briat JF (1997) Impact of iron deficiency and iron resupply during the early stages of vegetative development in maize (Zea mais L.). Plant Cell Environ. 20:1051-1060.

Thomine S, Vert G (2013) Iron transport in plants: better be safe than sorry. Curr Op Plant Biol. 16:322-327.

Valentinuzzi F, Pii Y, Carlo P, Roberto T, Fontanella MC, Beone GM, Astolfi S, Mimmo T, Cesco S (2020) Root-shootroot $\mathrm{Fe}$ translocation in cucumber plants grown in a heterogeneous Fe provision. Plant Sci. 293:110431.

Valipour M, Baninasab B, Khoshgoftarmanesh AH, Gholami M (2020) Oxidative stress and antioxidant responses to direct and bicarbonate induced iron deficiency in two quince rootstocks. Sci Hort. 261:108933.

Vizzotto G, Pinton R, Bomben C, Cesco S, Varanini Z, Costa, G (1999) Iron reduction in iron stressed plants of Actinidia deliciosa genotypes: involvement of PM Fe(III)-chelate reductase and $\mathrm{H}^{+}$-ATPase activity. J Plant Nutr. 22:479-488.

Wallace A, Lunt OR (1960) Iron chlorosis in horticultural plants. Ann Rev Proc Am Soc Hort Sci. 75:819-841.

Yi Y, Guerinot ML (1996) Genetic evidence that induction of root Fe ${ }^{\text {III }}$ chelate reductase activity is necessary for iron uptake under iron deficiency. Plant J. 10:835-844.

Yu H, Zou W, Chen J, Chen H, You Z, Huang J, Tang H, Wei X, Gao B (2019) Biochar amendment improves crop production in problem soils. J Environ Man. 232:8-21.

Zhao Y, Sun M, Liang Z, Li H, Yu F, Liu S (2020) Analysis of contrast iron chlorosis tolerance in the pear cV. 'Huangguan' grafted onto Pyrus betulifolia and quince A grown in calcareous soils. Sci Hort. 271:109488. 